\title{
Graafian follicle growth and replacement in anovulatory ovaries of ageing C57BL/6J mice
}

\author{
R. G. Gosden, Susan C. Laing, K. Flurkey* and C. E. Finch* \\ Department of Physiology, University Medical School, Teviot Place, Edinburgh EH8 9AG, U.K. and \\ * Department of Biological Sciences \& Andrus Gerontology Center, University of Southern California, \\ Los Angeles, California 90089, U.S.A.
}

\begin{abstract}
Summary. The growth of preantral follicles and replacement of large Graafian follicles was studied in reproductively senescent $\mathrm{C} 57 \mathrm{BL} / 6 \mathrm{~J}$ mice immediately after the loss of oestrous cyclicity when the ovary is approaching exhaustion of its follicular reserve. Granulosa cells were labelled in vivo by injection of tritiated thymidine and were evaluated by autoradiography. At $1 \mathrm{~h}$ after injection, labelling was confined almost exclusively to the cumulus and neighbouring cells whereas the distribution of labelled granulosa cells in preantral follicles was approximately uniform. The proportion of labelled mural cells in Graafian follicles rose from initially low values to maximal levels 3 days later; this suggested that those follicles that were Graafian at the time of injection had been replaced by recruitment of preantral stages. The rate of growth of preantral follicles was similar in senescent anovulatory mice and in young adult animals. A simple model was constructed to illustrate how persistent vaginal cornification in ageing mice is sustained by a stream of Graafian follicles and why some of the latter did not respond fully to an ovulatory dose of hCG.
\end{abstract}

\section{Introduction}

The frequency of oestrous cycles in C57BL/6J mice begins to decline by about 9 months of age and there is a corresponding increase in persistent vaginal cornification (Nelson, Felicio, Randall, Sims \& Finch, 1982). The latter condition results from the modest but sustained production of oestradiol (Nelson, Felicio, Osterburg \& Finch, 1981) during the underlying anovulatory state in which follicular maturation and secretion proceed while follicles become atretic rather than ovulate. A similar condition occurs in other strains of mice and rats, and is readily induced in younger rodents by agents that inhibit ovulation by interfering with the pro-oestrous surge of gonadotrophic hormones (Everett, 1964).

The turnover of large Graafian follicles in mice with persistent vaginal cornification was studied because persistence ('overripening') of anovulatory follicles has potential effects on recruitment of smaller types of growing follicles and on ovarian steroid output. Furthermore, the oocytes contained within these anovulatory follicles might have an increased risk of fetal mortality and heteroploidy if fertilized (Butcher, 1975; Mikamo \& Hamaguchi, 1975). In the present study, the turnover of large follicles and the growth rate of smaller types in anovulatory ovaries were estimated by labelling the granulosa cells with tritiated thymidine. The ability of the Graafian follicles to respond to an ovulatory dose of gonadotrophin was also determined. 


\section{Materials and Methods}

Animals. C57BL/6J mice were obtained from the Jackson Laboratory (Bar Harbor, ME, U.S.A.) as young virgins (and held until 4-7 months of age) or as retired breeders (and held until 13-15 months old). Animal husbandry conditions have been described by Nelson et al. (1981). A $12 \mathrm{~h} \mathrm{light-12} \mathrm{h}$ dark cycle began at $07: 00 \mathrm{~h}$, and mice were housed singly to maximize cycle regularity (Nelson $e t$ $a l .$, 1982). Vaginal smears were obtained each morning by lavage and stained with Giemsa to determine the stages of the oestrous cycle (Nelson et al., 1982). These age groups were chosen because younger animals of this strain have a moderately high incidence of 4- and 5-day cycles, whereas most ageing mice are acyclic and present persistent vaginal cornification.

Follicle turnover. Young mice $(\mathrm{N}=9)$ that had had two successive 4-day vaginal cycles and were at pro-oestrus, oestrus or met-oestrus I on the day of treatment and a further group of 28 old mice that had had cornified smears for $>14$ days were injected once i.p. with methyl- $\left[{ }^{3} \mathrm{H}\right]$ thymidine $(2$ $\mu \mathrm{Ci} . \mathrm{g}^{-1}$; sp. act. $5 \mathrm{Ci} . \mathrm{mm}^{-1}$; Amersham Corp., Arlington Heights, Illinois) in sterile saline at $11: 00-12: 00 \mathrm{~h}$. All of the young mice and 5 of the old ones were killed by cervical dislocation $1 \mathrm{~h}$ later; the remaining old mice were sampled at $24,48,72,144$ or $288 \mathrm{~h}$ after injection. Four controls of each group were injected with the same volume of saline $(9 \mathrm{~g} \mathrm{NaCl} / 1) 1 \mathrm{~h}$ before autopsy.

A similar group of 7 young, and 3 old mice received two injections of the radioactive tracer to compare the lengths of the S-phase in granulosa cells according to the double labelling method of Pedersen (1970) which was based on principles described by Wimber \& Quastler (1963). Each animal was given an initial dose of $0.4 \mu \mathrm{Ci} . \mathrm{g}^{-1}$, followed by a second injection of a larger dose, $4 \cdot 0$ $\mu \mathrm{Ci} . \mathrm{g}^{-1}, 1 \mathrm{~h}$ later. Mice were killed $0.75 \mathrm{~h}$ after the second injection.

At autopsy the ovaries were dissected out of their bursae and fixed for $2 \mathrm{~h}$ in aqueous Bouin's fluid. All mice were judged to be free of pathological lesions in their abdominal and thoracic cavities. Pituitary tumours and other gross lesions are rare in this strain at 15 months of age (Felicio, Nelson \& Finch, 1980). Fixed tissues were prepared for paraffin-wax embedding and were sectioned serially at $7 \mu \mathrm{m}$. Picric acid and thymidine in the acid-soluble pool were removed by immersing the mounted sections in a saturated solution of lithium carbonate and in ice-cold $5 \%$ trichloracetic acid, respectively. After thorough washing, the slides were coated in liquid nuclear emulsion (K2, Ilford Ltd, Basildon, Essex) at $46^{\circ} \mathrm{C}$, dried and exposed in light-proof boxes at $4^{\circ} \mathrm{C}$ for 3-8 weeks. Control slides were exposed at the same time to detect positive or negative chemographic effects (e.g. high background activity and latent image fading). Pilot studies indicated few artefactual changes in silver grain density. Slides were developed and fixed (D19 developer and Kodafix; Kodak Ltd, Liverpool) and stained lightly with haematoxylin and eosin.

The autoradiographs were studied at high magnification with oil-immersion optics $(\times 1000)$. The background density of grains was determined in experimental slides within $1 \mathrm{~mm}$ of the sections and above the tissue of control slides, and any having $>1$ grain per $100 \mu \mathrm{m}^{2}$ were discarded. Cell nuclei with three or more grains were considered to be labelled, since the probability of labelling of the average nuclear area of $31 \mu^{2}$ by chance was then $<0.004$ (by Poisson).

The labelling index (LI) in both ovaries of individual follicles, excluding primordial types, was determined in the section which passed through the nucleolus of the oocyte, and was the ratio of the number of labelled granulosa cells/total number of these cells. The numbers of cells counted per follicle section varied between 20 and 2000 according to the stage of development. Since pilot experiments showed that the LI varied within Graafian follicles, the cells were divided arbitrarily into two sub-populations for the purposes of analysis: Zone A comprised the cumulus cells and the immediately subjacent region of the membrana granulosa and Zone B comprised the remaining area of mural granulosa cells (Text-fig. 1).

The LIs in the double labelling experiment were obtained by a method similar to that of Pedersen (1970) and the results were expressed as the number of lightly labelled cells as a percentage of the total number of labelled cells. Labelled cells had 3 or more grains per nucleus and 


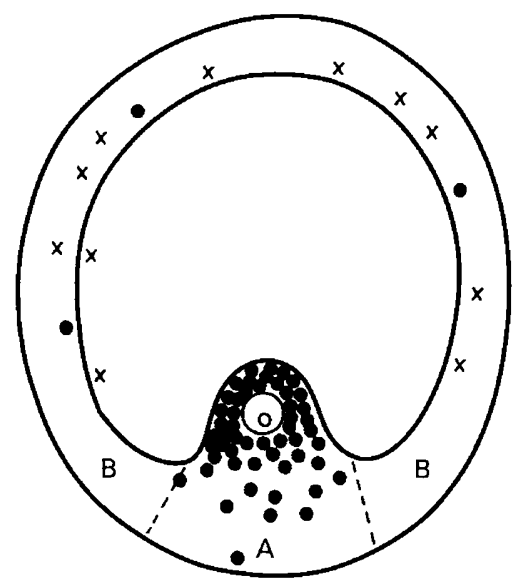

Text-fig. 1. Diagrammatic representation of the distribution of proliferating ( $)$ and dying (pycnotic) $(\times)$ granulosa cells in large Graafian follicles of anovulatory ageing mice. The limits of Zones A and B are shown since they defined the areas in which the labelling indices were determined.

those with 3-30 grains were considered to be lightly labelled, this being the upper limit for precise determination of the grain density.

Although follicles were sufficiently abundant in young ovaries for a random sample to be chosen for microscopical study, all follicles fulfilling the minimum criteria were analysed in old ovaries. The criteria were the presence of an intact and unwrinkled section of the whole follicle and an acceptably low background density of grains in the adjacent emulsion where it was not covering tissue. In general, only the non-atretic follicles were analysed, i.e. those with $<2$ pycnotic granulosa cells per section and without evidence of spontaneous maturation or degeneration of the oocyte. However, Graafian follicles at stage VIc in mice with persistent vaginal cornification are rarely devoid of pycnotic cells (Gosden, Laing, Felicio, Nelson \& Finch, 1983). Therefore this stringent criterion for atresia was relaxed for these types, although any with obvious degeneration of the oocyte or atresia of the follicular antrum were not analysed.

For convenience of description, ovarian follicles were classified according to the number of granulosa cell layers and the presence of an antrum (Mandl \& Zuckerman, 1951). In this classification, stages I-VI represent growth from primordial (I) to Graafian size (VI). Since stage VI includes a large range of sizes it was sub-divided: VIa (small antral types without a continuous fluid space), VIb (preovulatory antral types), VIc (large antral types which have undergone further cystic development beyond the size and appearance which is normally seen at pro-oestrus) (Gosden et al., 1983).

Follicular responsiveness to gonadotrophin. Another group of 7 mice aged 13-16 months and presenting persistently cornified smears were injected i.p. at 19:30 h with 1 or 5 i.u. hCG (Squibb, Princeton, NJ), both of which are ovulatory doses in young adult mice. A similar group of 5 controls were injected at the same time with saline $(9 \mathrm{~g} \mathrm{NaCl} / 1)$. Mice were killed at $1300-1600 \mathrm{~h}$ on the following day when the oviducts were dissected to recover any freshly ovulated masses of eggs. The ovaries were prepared as histological sections stained with haematoxylin and eosin.

\section{Results}

\section{Morphology of anovulatory ageing ovaries}

Ovaries of 13-15-month-old mice with persistent vaginal cornification always contained large Graafian follicles in stages VIb and VIc; VIc follicles were only occasionally seen in ovaries of 
young mice (see Gosden et al., 1983, for data). A few VIc follicles were haemorrhagic and most had some pycnotic granulosa cells, these being restricted to the mural region (1-50 per section). The old ovaries had few remaining primordial follicles in their cortex $(86 \pm 25$, mean \pm s.e.m. $)$ but recruitment of growing follicles was unimpeded. Corpora lutea were absent but stromal tissue was abundant and contained conspicuous masses of lipochrome cells.

\section{Follicular responsiveness of old anovulatory mice to $h C G$}

All old mice injected with hCG had fresh oocytes in the ampullae, but the saline-treated controls did not ovulate. The number of ova shed per ovulating mouse was not significantly affected by the dose of hCG ( 1 or 5 i.u.). Overall, $4.1 \pm 0.7$ ova were shed (mean \pm s.e.m.) which is significantly less than the numbers in comparable young mice $(P<0.01)$. All of the ovaries of hCG-injected mice contained some remaining Graafian follicles (generally VIc) with evidence of partial responses to hCG, such as resumption of meiotic maturation and mucification of cumulus cells. The oocytes of comparable follicles in control ovaries remained in dictyotene and without signs of follicular activation.

\section{Follicular turnover}

The distribution of labelled granulosa cells $1 \mathrm{~h}$ after injection of $\left[{ }^{3} \mathrm{H}\right]$ thymidine was approximately uniform in preantral follicles, but concentrated in the zone close to the oocyte (A) of Graafian follicles (Text-fig. 2; Pl. 1, Figs $1 \& 2$ ). This distinction was especially sharp in the largest cystic stages (VIc). The median LI for both types of large antral follicle was nearly $0 \cdot 3$ for Zone A, but generally much less than $0 \cdot 1$ in the mural cells (Zone B). The distribution of labelled nuclei varied continuously between the zones and there were gradients within each zone. Nevertheless, the distinctions between zones were sufficiently great to serve as markers for follicular turnover. Labelled cells were concentrated in the region of the cumulus oophorus of Zone A but decreased in frequency with distance from the oocyte. Labelled cells in Zone B tended to be restricted to the regions bordering the other zone and the follicular antrum, i.e. the cells that were closest to and had recently separated from the central zone of growth.

The median LI of Zone B increased with time after labelling as a result of the recruitment of follicles with a high LI and indicated that the set of Graafian follicles present at the time of labelling had been totally replaced within 3-4 days (Text-fig. 2; Pl. 1, Figs $3 \& 4$ ). Assuming that the mean rates of follicle recruitment and atresia are equivalent and constant, the LI of this zone should increase linearly with time. However, the expected increase of the LI in the 24-h sample was not obtained, though this might simply be chance variation. The LI was maximal at $72 \mathrm{~h}$ and significantly higher than at $1 \mathrm{~h}(P<0 \cdot 01$, Wilcoxon test $)$ and was maintained at the same level at

\section{PLATE 1}

Figs 1 and 2. Autoradiographs of a large Graafian follicle in a 15-month-old mouse prepared $1 \mathrm{~h}$ before autopsy by injection with $\left[{ }^{3} \mathrm{H}\right]$ thymidine. The substantial majority of labelled granulosa cell nuclei were located within the cumulus region and the subjacent cells of the granulosa cell membrane. Serial reconstruction of this follicle showed that the labelled cells on the left side of the follicle wall were in fact located close to an extended but irregular mass of cumulus cells. Fig. 1, bright field illumination, $\times 104$; Fig. 2, dark-ground illumination, $\times 104$.

Figs 3 and 4. Autoradiographs of a large Graafian follicle in a 15-month-old mouse killed $48 \mathrm{~h}$ after injection of $\left[{ }^{3} \mathrm{H}\right]$ thymidine. Labelled granulosa cells are present in the wall of the follicle opposite to the cumulus region. The grain density of cumulus cells has become diluted through subsequent mitosis. The background activity over the antrum is higher than that in Fig. 1. Fig. 3 , bright field illumination, $\times 207$; Fig. 4, dark-ground illumination, $\times 207$. 

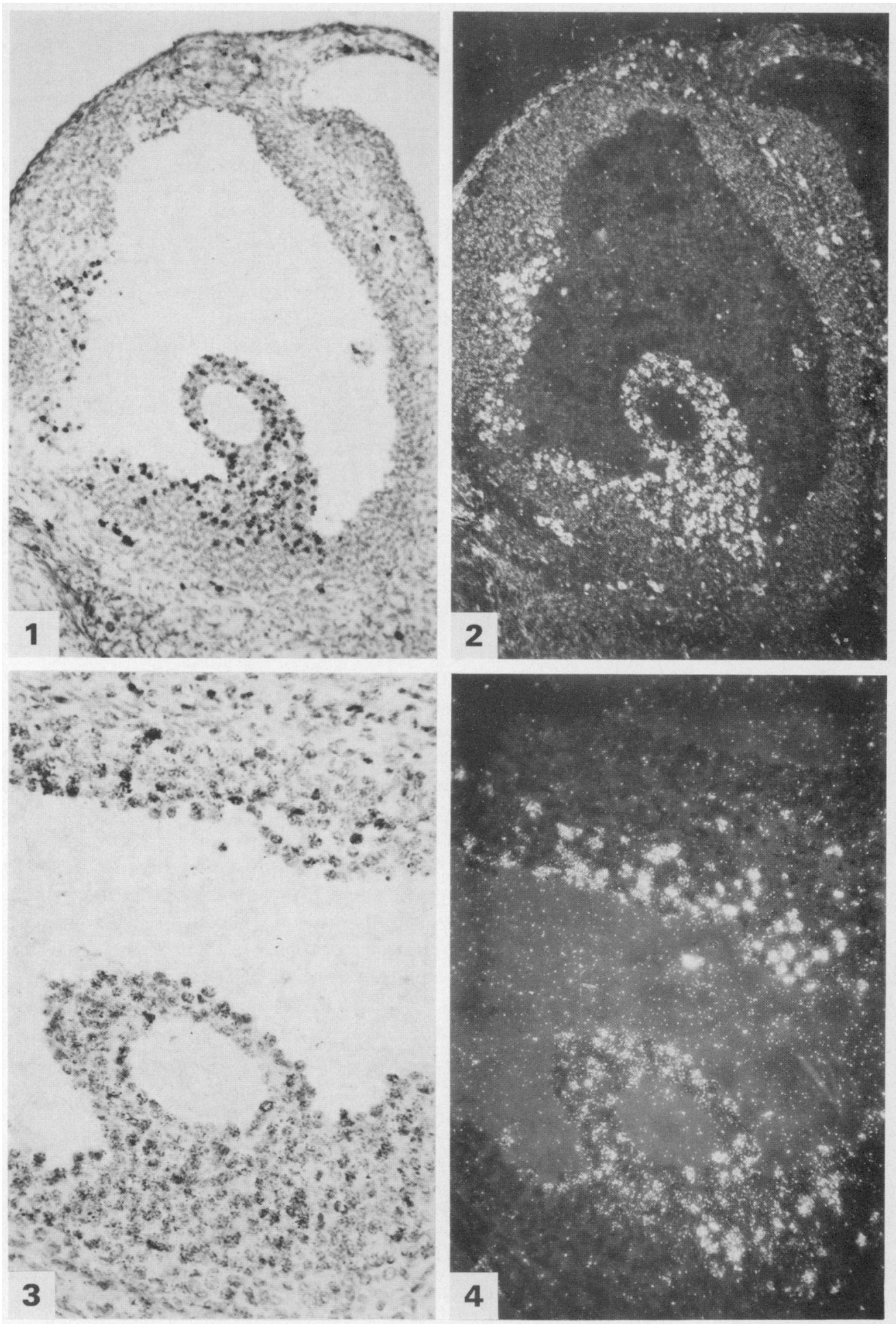


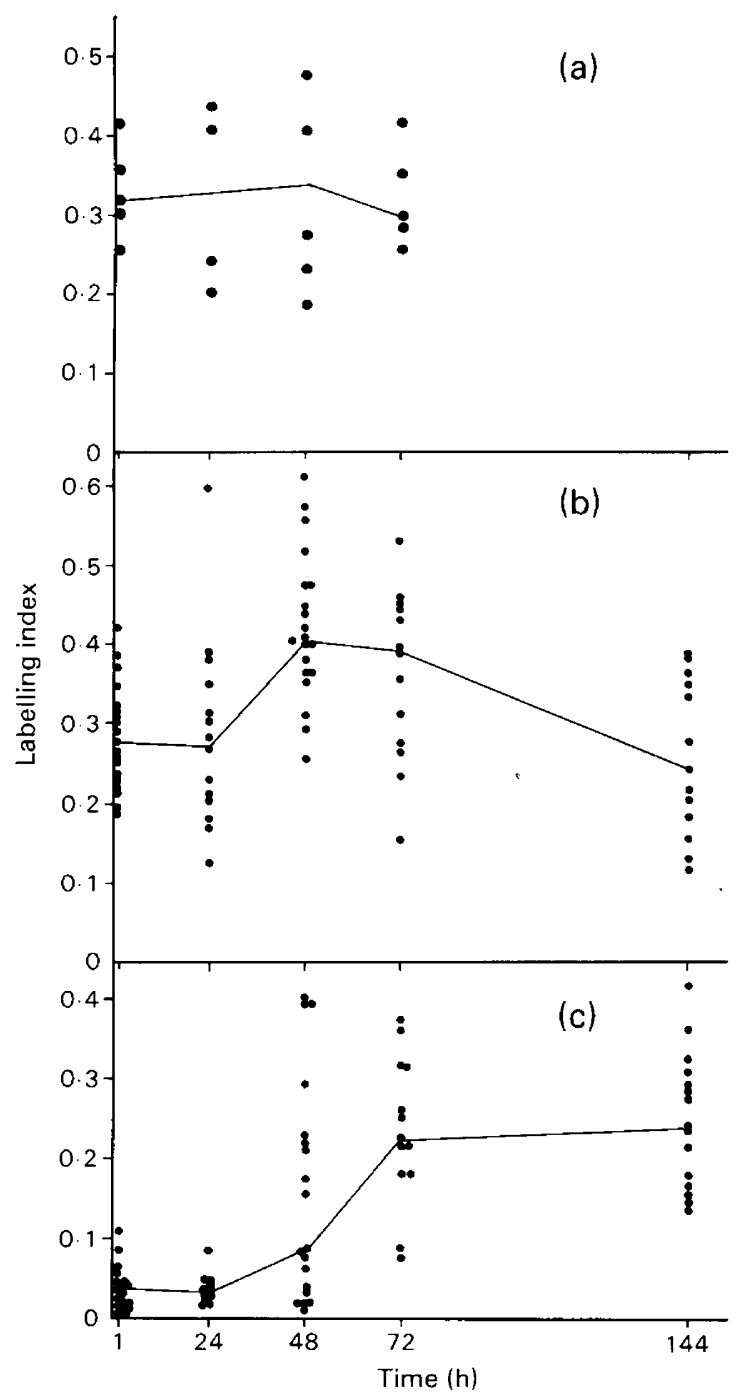

Text-fig. 2. The variation of the labelling index in granulosa cells of (a) small (VIa) and (b, c) large $(\mathrm{VIb}+\mathrm{c})$ Graafian follicles in 13-15-month-old mice that had been treated with a single injection of $\left[{ }^{3} \mathrm{H}\right]$ thymidine $\left(\right.$ at $\left.\mathrm{t}_{0}\right)$. Each point represents one follicle and the lines are the medians. Since the labelling patterns of cells in follicles of stages VIb and VIc were heterogeneous within follicles, the LI was determined for two distinct sub-populations or zones (see Text-fig. 1); i.e. Zone A (b) and Zone B (c). The LI in Zone B was significantly higher at $48 \mathrm{~h}(P<0.02) 72$ and $144 \mathrm{~h}(P<0.01)$ than at $1 \mathrm{~h}$ (Wilcoxon test).

$144 \mathrm{~h}$. Observations of the final group ( $288 \mathrm{~h}$ ) could not be interpreted because the signal to noise ratio was substantially reduced by successive cell divisions. A further prediction arising from the preceding assumptions is that follicles with a high LI at 48 and $72 \mathrm{~h}$ (i.e. newly recruited from the growing pool) would have fewer pycnotic cells than the remaining ones with a lower LI. Whilst there was some evidence of this, it was not confirmed statistically because of variations in the percentage of pycnotic cells. The proportion of follicles with a high LI did not vary with the size of the total population of follicles remaining. 
The LI of Zone A was high at all times after the single injection of $\left[{ }^{3} \mathrm{H}\right]$ thymidine, as would be expected of a relatively homogeneous population of dividing cells (Text-fig. 2). The values tended to be slightly higher at 48 and $72 \mathrm{~h}$ in association with an unusually high grain density over the antrum (Pl. 1, Figs $3 \& 4)$, a phenomenon which has been attributed to release of labelled nucleoside from dying cells and subsequent re-uptake (Byskov, 1974). Although we could not determine the density of grains per nucleus in heavily labelled cells ( $>30$ grains), it was our firm impression that the heavily labelled cells had a similar density both between and within the two zones $1 \mathrm{~h}$ after labelling. However, the grain density appeared to diminish more rapidly in Zone A than in Zone B in subsequent autoradiographs, and within Zone $A$ the degree of dilution seemed to vary inversely with distance from the oocyte. Continuing growth of Zone A appeared to contribute few cells to the mural population since the LI of the latter remained very low in some of the follicles. Instead, proliferation appeared to result in the lateral expansion of the cumulus oophorus, thus producing a broad platform of cells.

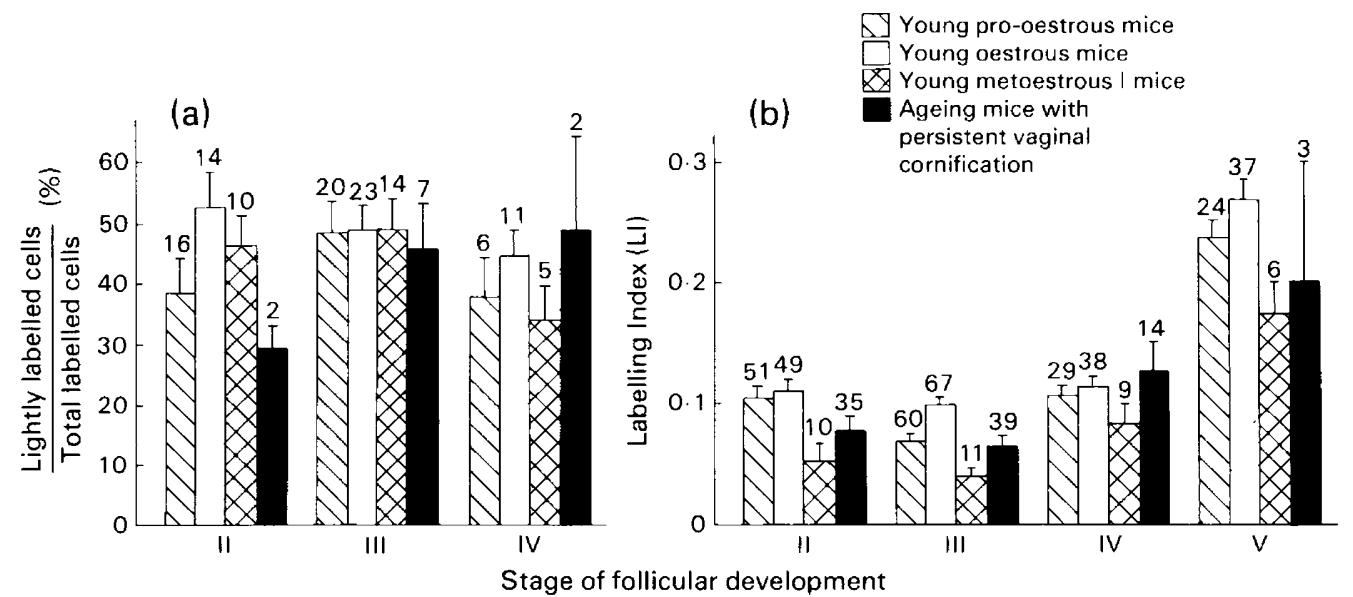

Text-fig. 3. The labelling of granulosa cells in the ovaries of young and ageing mice: (a) the percentages of lightly labelled cells, giving an index of S-phase length, and (b) the labelling index. Values are mean \pm s.e.m. for the no. of observations indicated.

The LI of medium-sized growing follicles (II-V) in young mice seemed to vary consistently with stages of the oestrous cycle, although the differences were not statistically significant (Text-fig. 3, $P$ $<0.05$ by Newman-Keul's studentized range test). The LI varied with the stage of follicular development: those of the largest preantral types (V) were similar to the values of Zone $A$ of Graafian follicles, and significantly higher than those of smaller types (II-IV) $(P<0.05)$. The LIs of follicles in old ovaries were within the normal range of variation of young cyclic animals.

The length of the S-phase of granulosa cells in the two age groups was compared because it is possible for follicles to have a similar LI yet still grow at different rates. Differences in the proportions of lightly labelled cells in double labelling experiments provided an indication of differences of the S-phase. However, the proportions were not significantly different for follicle stages II-IV (Text-fig. 3); no estimates are provided for stage $\mathrm{V}$ because of the small numbers of such follicles in old ovaries.

\section{Discussion}

The principal conclusion of these results is that a set of Graafian follicles in ageing anovulatory mice is replaced completely in 3-4 days. This information, combined with additional data, has been 
used to construct a hypothetical model to explain the growth and replacement of Graafian follicles in animals with persistent vaginal cornification.

The evidence of a short lifespan of unovulated Graafian follicles was based on the differential pattern of granulosa cell proliferation $\left(\left[{ }^{3} \mathrm{H}\right]\right.$ thymidine incorporation) which was characteristic of these follicles. Mural cells had very low levels of radioactivity whereas the activity of cumulus cells was high and comparable with that of preantral follicles in which cells were labelled more or less randomly. It follows, therefore, that the increased LI over a 3-day period after a pulse of $\left[{ }^{3} \mathrm{H}\right]$ thymidine implies that the original set of Graafian follicles labelled at the time of injection had been replaced by follicles that were preantral at that time. The method indicates replacement of the whole population but cannot provide information about the longevity of individual follicles.

The lifespan of Graafian follicles in ageing anovulatory ovaries is similar to their potential longevity in cyclic rats and hamsters, as disclosed by barbiturate sedation to suppress the spontaneous ovulatory surge of gonadotrophins. Unovulated follicles undergo atresia spontaneously 3 or 4 days after pro-oestrus in these animals (Everett \& Sawyer, 1950; Braw \& Tsafriri, 1980; Terranova, 1980), although this interval is shorter in 5-compared to 4-day cycles (van der Schoot, 1980) and is slightly longer in PMSG-treated immature rats than in adults (Terranova \& Ascanio, 1982).

The morphological appearance and secretory activity of these unovulated follicles has been studied to identify factors responsible for atresia. Many follicles in ageing ovaries became haemorrhagic before other signs of involution, such as extensive granulosa cell pycnosis. Accidental breaches of the integrity of the follicular wall might therefore be responsible for atresia in some follicles.

Another factor of potential significance is the changing pattern of steroid production in postmature follicles and their diminished response to LH. Such changes may promote apoptosis rather than mitosis, thereby leading to atresia. Perhaps the most significant changes are the decreased production in vitro by explanted follicles of oestradiol and androgens and the concomitant increased production of progesterone, which might reflect impaired ability to convert progesterone to androgens (Braw \& Tsafriri, 1980; Uilenbroek, Woutersen \& van der Schoot, 1980; Terranova, 1981). There is evidence that a balance between the levels of oestradiol and androgens determines whether follicles continue their growth or become atretic (Harman, Louvet \& Ross, 1975; Bagnell, Mills, Costoff \& Mahesh, 1982). The reduced ability of unovulated follicles to produce oestradiol might partly explain why plasma hormone levels of mice with persistent vaginal cornification are less than those of pro-oestrous mice (Nelson et al., 1981) even though both types of mice have ovaries dominated by large follicles. Graafian follicles that become post-mature also show lower specific binding of gonadotrophins (Peluso, Steger \& Hafez, 1977; Uilenbroek et al., 1980) and a weaker ovulation response to $\mathrm{LH}$ which may be attributable to decreased intra-follicular oestradiol.

These changes affecting post-mature follicles may be considered as pathological or as further stages of differentiation, but they result in follicles that are incapable of a full response to gonadotrophic stimuli. The oocyte, however, retains a normal morphological appearance until there is extensive granulosa cell pycnosis and it remains capable of responding to gonadotrophic stimulation. This suggests that the oocyte does not initiate atresia, although its developmental potential may be affected adversely by prolonged sojourn in the follicle while it remains ovulable (Butcher \& Pope, 1979; Martin \& Terranova, 1982). The partial responses of some follicles to hCG (e.g. meiotic maturation without ovulation and luteinization) suggest that actions of gonadotrophins that are mediated by prostaglandins are preferentially affected during atresia (see Tsafriri, Lindner, Zor \& Lamprecht, 1972).

Maintenance of a set of Graafian follicles in anovulatory ageing mice is illustrated by a model in Text-fig. 4, although the model might be equally applicable to younger animals with polyfollicular ovaries and persistent vaginal cornification. Each horizontal array of follicles indicates their flow from the time of origin on the left until they disappear by atresia a few days later. Atresia and replacement of individual follicles was assumed to be asynchronous since there was no 


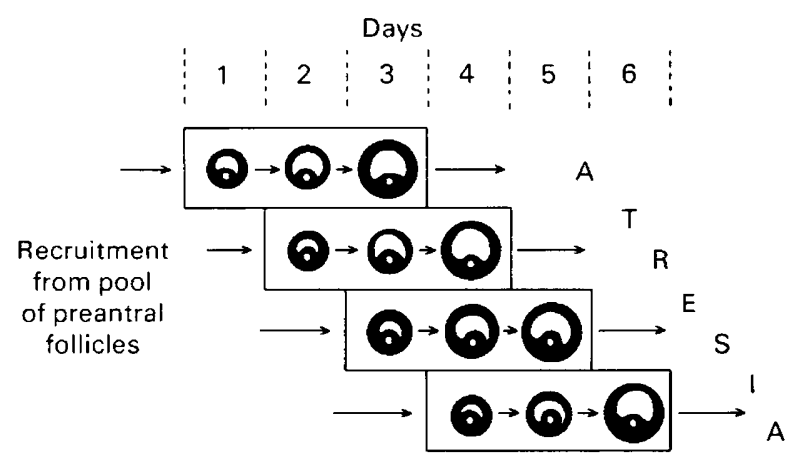

Text-fig. 4. Schematic representation of the turnover of large Graafian follicles in ageing anovulatory mice. Each horizontal panel indicates the continuity in growth of a single follicle through Graafian maturity (stages VIa, VIb, VIc) until it loses its responsiveness to ovulatory stimuli and becomes atretic. This period is approximately 3 days.

morphological evidence of discontinuous progression of follicles, neither would this be expected where the normal synchronizing event (the FSH surge) was absent (Hoak \& Schwartz, 1980). If the time taken for individual follicles to progress through these stages to atresia is approximately constant and independent of the size of the total follicular population remaining, it follows that about one-third of the Graafian stages will become atretic each day. The numbers of follicles at a given stage of development or atresia will vary since the Graafian follicle population is not an open system in a steady state because the flow rate is limited by the numbers of follicles available for recruitment (Faddy, Gosden \& Edwards, 1983). Consequently, there will be an increasing probability during ageing that persistent vaginal cornification will be punctuated by intermittent and eventually chronic leucocytosis without pseudopregnancy, signifying exhaustion of large secretory follicles. Healthy $\mathrm{C} 57 \mathrm{BL} / 6 \mathrm{~J}$ mice generally present persistent vaginal leucocytosis when they are 20-26 months old (Gee, Flurkey \& Finch, 1983).

During the period when ovarian function is waning the rates of growth of medium-sized follicles do not change, despite the rise in levels of plasma LH and FSH reported to occur at 16 months of age (Parkening, Collins \& Smith, 1980). This conclusion is drawn from the similar labelling index and percentage of lightly labelled cells in young cyclic and acyclic ageing mice and is consistent with previous studies, although Pederson (1972) and Faddy et al. (1983) did not distinguish the stages of the ovarian cycle. A change of the dynamics of growth of follicles would not be expected to result from the transition to anovulatory state per se since the longevity of large follicles does not exceed the normal length of the oestrous cycle, but it is important to discover whether the circulating levels of gonadotrophins are elevated as early as 13-15 months of age in these mice.

Earlier studies provided limited evidence of a distinction between the growth rates of mural and cumulus cells (Bullough, 1942; Pedersen, 1970) which are confirmed here. Organization of follicular growth might be compared with that of other epithelia in which a small focus of selfmaintaining stem cells produces some progeny cells ('transit cells') which amplify the cellular reproductive activity and which lead, in turn, to cells with a higher probability of differentiation and a decreasing probability of self-replication (Potten, Schofield \& Lajtha, 1979). Cells within the cumulus oophorus may contain a stem-type cell population which provides the focus of growth and a source of differentiating cells that migrate centrifugally. This pattern of growth may have important developmental repercussions if the follicle receives an effective ovulatory stimulus after reaching normal preovulatory ripeness (stages VIb-VIc). The additional granulosa cells remain at one pole of the follicle and distort the normal architecture of the cumulus, perhaps leading to 
impairment in the shedding of the oocyte and resulting in corpora lutea accessoria, structures that are frequently seen in ageing mouse ovaries (Jones \& Krohn, 1961). On the other hand, continuing cell death amongst the mural cells without cell replacement may affect the ultimate size of the corpus luteum which is formed after delayed ovulation. Nevertheless, the potential significance of any effects of delayed ovulation on the future corpus luteum and oocyte may be overruled by intervening refractoriness of the follicle to the ovulatory stimulus.

We gratefully acknowledge a project grant from the Medical Research Council to R.G.G. and grants from the National Institute of Aging (AG-00117, AG-00443) to C.E.F. R.G.G. was in receipt of travel grants from the Wellcome Trust and the Carnegie Trust for the Universities of Scotland and K.F. was supported by a N.I.A. Training grant (5T32-AG-00037).

\section{References}

Bagnell, C.A., Mills, T.M., Costoff, A. \& Mahesh, V.B. (1982) A model for the study of androgen effects on follicular atresia and ovulation. Biol. Reprod. 27, 903914.

Braw, R.H. \& Tsafriri, A. (1980) Follicles explanted from pentobarbitone-treated rats provide a model for atresia. J. Reprod. Fert. 59, 259-265.

Bullough, W.S. (1942) The method of growth of the follicle and corpus luteum in the mouse ovary. $J$. Endocr. 3, 150-156.

Butcher, R.L. (1975) The role of intrauterine environment and intrafollicular aging of the oocyte on implantation rates and development. In $\mathrm{Aging} \mathrm{Ga}$ metes: their Biology and Pathology, pp. 201-218. Ed. R. J. Blandau. S. Karger, Basel.

Butcher, R.L. \& Pope, R.S. (1979) Role of estrogen during prolonged estrous cycles of the rat on subsequent embryonic death or development. Biol. Reprod. 21, 491-495.

Byskov, A.G.S. (1974) Cell kinetic studies of follicular atresia in the mouse ovary. J. Reprod. Fert. 37, 277285.

Everett, J.W. (1964) Central neural control of reproductive functions of the adenohypophysis. Physiol. Rev. 44, 373-431.

Everett, J.W. \& Sawyer, C.H. (1950) A 24-hour periodicity in the "LH-release apparatus" of female rats, disclosed by barbiturate sedation. Endocrinology 47, 198-218.

Faddy, M.J., Gosden, R.G. \& Edwards, R.G. (1983) Ovarian follicle dynamics in mice: a comparative study of three inbred strains and an $F_{1}$ hybrid. $J$. Endocr. 96, 23-33.

Felicio, L.S., Nelson, J.F. \& Finch, C.E. (1980) Spontaneous pituitary tumorigenesis and plasma oestradiol in ageing female C57BL/6J mice. Expl Geront. 15, 139143.

Gee, D.M., Flurkey, K. \& Finch, C.E. (1983) Aging and the regulation of luteinizing hormone in $\mathrm{C} 57 \mathrm{BL} / 6 \mathrm{~J}$ mice: impaired elevations after ovariectomy and spontaneous elevations at advanced ages. Biol. Reprod. 28, 598-607.
Gosden, R.G., Laing, S.C., Felicio, L.S., Nelson, J.F. \& Finch, C.E. (1983) Imminent oocyte exhaustion and reduced follicular recruitment mark the transition to acyclicity in aging mice. Biol. Reprod. 28, 255260.

Harman, S.M., Louvet, J.P. \& Ross, G.T. (1975) Interaction of estrogen and gonadotropins on follicular atresia. Endocrinology 96, 1145-1152.

Hoak, D.C. \& Schwartz, N.B. (1980) Blockade of recruitment of ovarian follicles by suppression of the secondary surge of follicle-stimulating hormone with porcine follicular fluid. Proc. natn. Acad. Sci. U.S.A. 77, 4953-4956.

Jones, E.C. \& Krohn, P.L. (1961) The relationships between age, numbers of oocytes and fertility in virgin and multiparous mice. J. Endocr. 21, 469-495.

Mandl, A.M. \& Zuckerman, S. (1951) The numbers of normal and atretic oocytes in unilaterally spayed rats. J. Endocr. 7, 112-119.

Martin, N.C. \& Terranova, P.F. (1982) Effects of delayed ovulation on pregnancy in the PMSG-treated immature rat. Proc. Soc. exp. Biol. Med. 169, 226-232.

Mikamo, K. \& Hamaguchi, H. (1975) Chromosomal disorder caused by preovulatory overripeness of oocytes. In Aging Gametes: their Biology and Pathology, pp. 72-97. Ed. R. J. Blandau. S. Karger, Basel.

Nelson, J.F., Felicio, L.S., Osterburg, H.H. \& Finch, C.E. (1981) Altered profiles of estradiol and progesterone associated with prolonged estrous cycles and persistent cornification in aging $\mathrm{C} 57 \mathrm{BL} / 6 \mathrm{~J}$ mice. Biol. Reprod. 24, 784-794.

Nelson, J.F., Felicio, L.S., Randall, P.K., Sims, C. \& Finch, C.E. (1982) A longitudinal study of estrous cyclicity in aging C57BL/6J mice: $\mathrm{I}$. Cycle frequency, length, and vaginal cytology. Biol. Reprod. 27, 327339.

Parkening, T.A., Collins, T.J. \& Smith, E.R. (1980) Plasma and pituitary concentrations of LH, FSH and prolactin in aged female $\mathrm{C} 57 \mathrm{BL} / 6 \mathrm{~J}$ mice. J. Reprod. Fert. 58, 377-386.

Pedersen, T. (1970) Follicle kinetics in the ovary of the cyclic mouse. Acta endocr., Copenh. 64, 304-323. 
Pedersen, T. (1972) Follicle growth in the mouse ovary. In Oogenesis, pp. 361-376. Eds J. D. Biggers \& A. W. Schuetz. University Park Press, Baltimore.

Peluso, J.J., Steger, R.W. \& Hafez, E.S.E. (1977) Sequential changes associated with the degeneration of preovulatory rat follicles. J. Reprod. Fert. 49, 215218.

Potten, C.S., Schofield, R. \& Lajtha, L.G. (1979) A comparison of cell replacement in bone marrow, testis and three regions of surface epithelium. Biochim. Biophys. Acta 560, 281-299.

Terranova, P.F. (1980) Effects of phenobarbital-induced ovulatory delay on the follicular population and serum levels of steroids and gonadotropins in the hamster: a model for atresia. Biol. Reprod. 23, 92-99.

Terranova, P.F. (1981) Steroidogenesis in experimentally induced atretic follicles of the hamster: a shift from estradiol to progesterone synthesis. Endocrinology 108, 1885-1890.
Terranova, P.F. \& Ascanio, L.E. (1982) Alterations of ovarian steroidogenesis induced by ovulatory delay in immature rats treated with pregnant mare serum gonadotropin. Biol. Reprod. 26, 129-139.

Tsafriri, A., Lindner, H.R., Zor, U. \& Lamprecht, S.A. (1972) Physiological role of prostaglandins in the induction of ovulation. Prostaglandins 2, 1-10.

Uilenbroek, J.Th.J., Woutersen, P.J.A. \& van der Schoot, P. (1980) Atresia of preovulatory follicles: gonadotropin binding and steroidogenic activity. Biol. Reprod. 23, 219-229.

van der Schoot, P. (1980) Delay of ovulation in rats with sodium pentobarbitone: apparent differences between rats with $4-$ or 5 -day reproductive cycles. $J$. Endocr. 86, 451-457.

Wimber, D.E. \& Quastler, H. (1963) A ${ }^{14} \mathrm{C}$ - and ${ }^{3} \mathrm{H}-$ thymidine double labelling technique in the study of cell proliferation in Tradescantia root tips. Expl Cell Res. 30, 8-22.

Received 24 January 1983 